\title{
PENGARUH KINERJA KEUANGAN TERHADAP RISIKO KEBANGKRUTAN BANK UMUM SYARIAH DI INDONESIA (METODE ALTMAN Z-SCORE MODIFIKASI)
}

\author{
Luluk Afiqoh \\ Departemen Ekonomi Syariah,Fakultas Ekonomi dan Bisnis,Universitas Airlangga \\ Email: lulukafiqoh1@gmail.com \\ Nisful Laila \\ Departemen Ekonomi Syariah,Fakultas Ekonomi dan Bisnis,Universitas Airlangga \\ Email: nisful.laila@feb.unair.ac.id
}

\section{ARTICLE HISTORY}

Received:

16 Desember 2018

Accepted:

29 Desember 2018

Online available:

31 Desember 2018

Keywords:

Financial

Performance,

Islamic

Commercial Bank, Risk of Bankruptcy, Altman Z-Score Modification.

\section{ABSTRACT}

This research aims to find out the influence of financial performance measured using the Capital Adequacy Ratio variable, Financing to Deposit Ratio, Leverage, Bank Size, Loan to Asset Ratio and Return on Assets to the risk of sharia bank bankruptcy in Indonesia during 2011-2017 calculated using the Altman Z-Score method Modification. This study uses a quantitative approach with panel data regression analysis techniques.

The results of this study show partially the variable Capital Adequacy Ratio, Financing to Deposit Ratio, Bank Size has a significant positive effect, the variable Loan to Asset Ratio Leverage has a significant negative effect, and Return on Asset has a positive and insignificant effect. Nevertheles the variable Capital Adequacy Ratio, Financing to Deposit Ratio, Leverage, Bank Size, Loan to Asset Ratio and Return on Asset have a significant effect on the value of Altman ZScore as a measure of the risk of bankruptcy in Islamic commercial banks in Indonesia.

\section{ABSTRAK}

Tujuan penelitian ini adalah mengetahui pengaruh kinerja Kata Kunci:

Kinerja Keuangan, keuangan yang diukur menggunakan variabel Capital Adequacy Ratio, Bank Umum Syariah, Risiko Financing to Deposit Ratio, Leverage, Bank Size, Loan to Asset Ratio dan Return on Asset terhadap risiko kebangkrutan bank umum syariah Kebangkrutan, Altman Z-Score di Indonesia pada 2011-2017 yang dihitung menggunakan metode Altman Z-Score Modifikasi. Penelitian ini menggunakan pendekatan Modifikasi. kuantitatif dengan teknik analisis data panel. Hasil penelitian ini menunjukkan secara parsial variabel Capital Adequacy Ratio, Financing to Deposit Ratio, Bank Size berpengaruh positif signifikan, 
variabel Rasio Leverage Loan to Asset Ratio berpengaruh negatif signifikan serta Return on Asset berpengaruh positif tidak signifikan. Meskipun demikian variabel Capital Adequacy Ratio, Financing to Deposit Ratio, Leverage, Bank Size, Loan to Asset Ratio dan Return on Asset berpengaruh signifikan terhadap nilai Altman Z-Score sebagai pengukur risiko kebangkrutan pada bank umum syariah di Indonesia.

\section{PENDAHULUAN}

Industri keuangan syariah di Indonesia saat ini berkembang cukup pesat, terutama di dalam sektor perbankan syariah. Perkembangan perbankan syariah di Indonesia terlihat peningkatannya tahun 1998 pada saat terjadinya krisis moneter yang menimpa Indonesia. Krisis tersebut menyebabkan kebangkrutan yang dialami oleh bank konvensional. Hal itu dikarenakan nilai tukar mata uang rupiah terhadap dollar semakin mengalami penurunan. Sedangkan masyarakat semakin banyak melakukan transaksi pembelian dollar sehingga permintaan terhadap dollar meningkat. Selain itu tingginya tingkat suku bunga yang ditetapkan Bank Indonesia, tingginya kredit macet yang disebabkan nasabah serta masalah likuiditas yang dialami oleh bank konvensional, tingkat inflasi yang tinggi serta kondisi Indonesia yang tidak stabil menyebabkan penarikan uang oleh nasabah secara besar-besaran di bank yang pada akhirnya berdampak buruk terhadap perekonomian Indonesia (Khadapi, 2017)

Kondisi bank konvensional pada masa itu berbeda dengan kondisi bank syariah. Bank syariah justru mengalami kondisi yang stabil. Hal ini ditunjukkan dengan masuknya Bank Muamalat Indonesia yang merupakan bank syariah pertama kali di Indonesia masuk sebagai kategori bank sehat yang tidak berpotensi mengalami kolaps atau bankrupt pada krisis 1997-1998 pada hasil pengumuman Badan Pengawas Perbankan Nasional (BPPN) pada Tanggal 13 Maret 1999 (Syinta 2018). Dengan kondisi tersebut menunjukkan kondisi krisis pada tahun 1998 tersebut tidak berdampak pada bank syariah karena kegiatan operasional bank syariah tidak berdasarkan pada tingkat suku bunga melainkan dengan menggunakan sistem bagi hasil. Setelah terjadinya krisis tersebut perkembangan bank syariah cukup besar. Berkembangnya bank syariah ini ditandai dengan semakin banyak jumlah perbankan syariah di Indonesia. Menurut data Statistik Perbankan Syariah dari Otoritas Jasa Keuangan sampai September 2018 jumlah BUS sebanyak 13 buah, UUS 21 buah dan BPRS 168 buah. Hal ini disebabkan semakin dikenalnya keberadaan perbankan syariah. Masyarakat banyak yang mulai tertarik dan menggunakan produk bank syariah dengan melakukan penyimpanan dan pembiayaan pada bank syariah.

Pertumbuhan perbankan syariah di Indonesia mengalami peningkatan setiap tahunnya. Hal ini terbukti dengan peningkatan aset sampai Juni 2018 sebesar 433.203 miliar. Selain itu, DPK yang disalurkan kepada nasabah juga mengalami 
kenaikan terus menerus sampai Juni 2018 sebesar 341.216 miliar yang diikuti dengan meningkatnya pembiayaan yang disalurkan sebesar 295.021 miliar pada bulan Juni 2018. Ini menunjukkan bahwa perbankan syariah di Indonesia mulai diminati dan dikenal oleh masyarakat serta merasa tertarik untuk menggunakan produk di perbankan syariah.

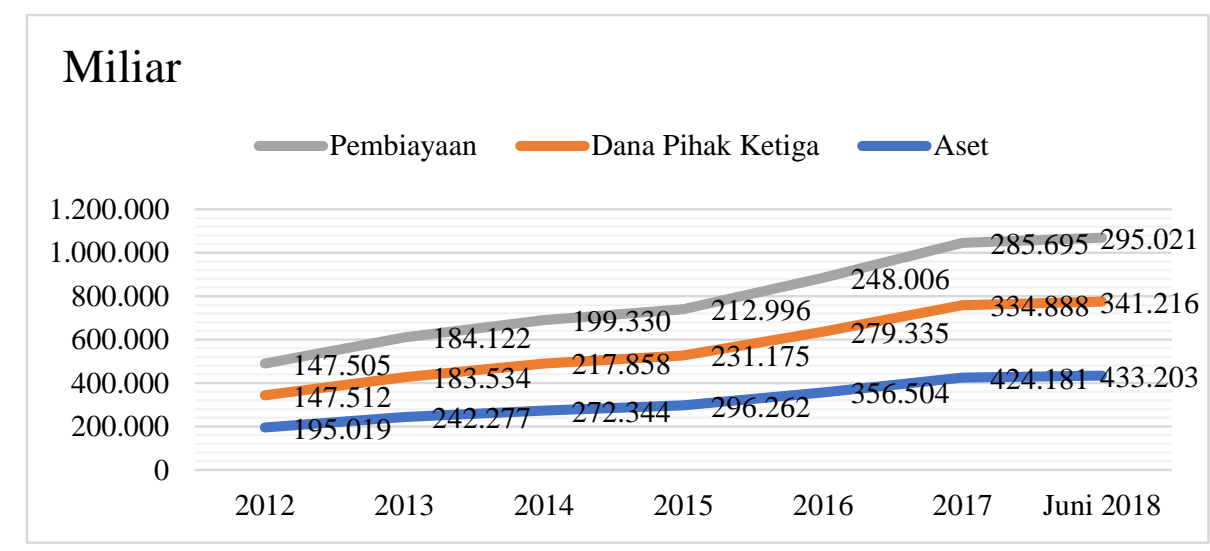

Sumber: Statistik Perbankan Syariah, Otoritas Jasa Keuangan

Gambar 1

Pertumbuhan Aset, Pembiayaan dan DPK Perbankan Syariah

Seiring dengan perkembangan bank syariah di Indonesia yang cukup pesat, bank syariah tetap akan menghadapi berbagai permasalahan dalam menjalankan fungsinya sebagai lembaga intermediasi. Ditambah dengan kondisi perekonomian di Indonesia yang masih fluktuatif. Hal ini disebabkan oleh perubahan kondisi ekonomi, sosial maupun politik yang dapat menyebabkan terjadinya krisis moneter sewaktuwaktu seperti yang pernah terjadi pada tahun 1998. Sampai saat ini, pertumbuhan bank syariah masih mengalami stagnasi yakni sebesar 5,5\% (OJK, 2017). Hal ini disebabkan karena masih adanya kendala yang dialami oleh bank syariah. Menurut Otoritas Jasa Keuangan (2017) kendala yang masih dialami oleh bank syariah adalah terkait permodalan, sumber daya manusia, dan kekuatan regulasi. Akibat kondisi tersebut, menimbulkan banyak risiko yang akan dihadapi oleh setiap perusahaan termasuk bank syariah. Risiko merupakan sebuah permasalahan yang pasti akan dihadapi oleh setiap entitas bisnis. Sebab setiap keuntungan yang akan diperoleh perusahaan selalu ada risiko yang akan dihadapi (Badri dalam Aji, 2017). Risiko merupakan sebuah sunatullah, sehingga manusia tidak dapat menghindar dari risiko yang akan dihadapi melainkan hanya bisa melakukan usaha untuk menghilangkan atau mengurangi risiko tersebut. Hal ini sesuai dengan firman Allah dalam surat Al Luqman ayat 34 yang berbunyi: 


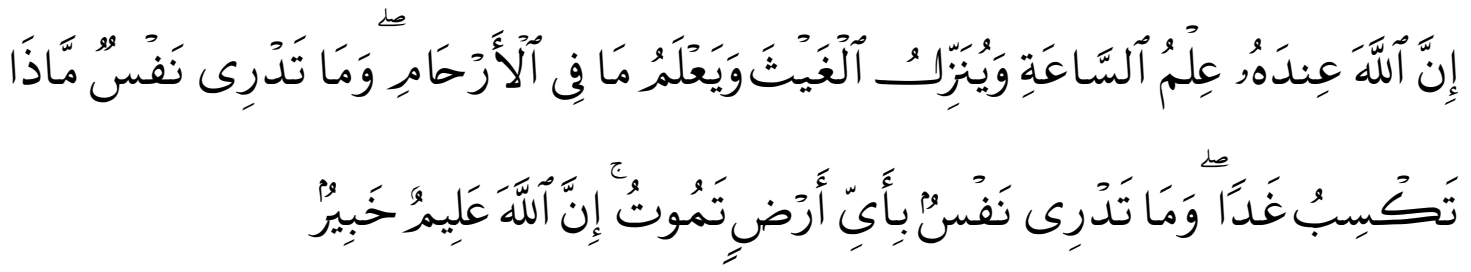

Innallāha 'indahụ 'ilmus-sā'ah, wa yunazzilul-gaīs, wa ya'lamu mā fil-ar-ḥām, wa mā tadrī nafsum mā̇̇ā taksibu gadā, wa mā tadrī nafsum bi ayyi arḍin tamụt, innallāha 'alïmun khabìr

Artinya: "Sesungguhnya Allah, hanya pada sisi-Nya sajalah pengetahuan tentang hari kiamat dan Dialah yang menurunkan hujan, dan mengetahui apa yang ada dalam rahim. Dan tiada seorangpun yang dapat mengetahui (dengan pasti) apa yang akan diusahakannya besok. Dan tiada seorangpun yang dapat mengetahui di bumi mana dia akan mati. Sesungguhnya Allah Maha Mengetahui lagi Maha Mengenal". (QS. 31: 34, Departemen Agama RI, 2018).

Tafsir dari ayat di atas menjelaskan hanya Allah yang mengetahui segala apa yang ghaib dan nampak, hal yang lahir dan batin. Allah menampakkan beberapa perkara kepada hamba-Nya serta ada perkara yang juga disembunyikan dari seluruh manusia. Oleh sebab itu manusia tidak dapat mengetahui apa yang akan terjadi pada dirinya untuk ke depan, melainkan hanya bisa berusaha dan berdoa kepada Allah (Abdurrahman, 2016:555-556).

Salah satu risiko yang dihadapi oleh bank syariah adalah terkait risiko kebangkrutan. Menurut Oktarina (2017:10) risiko kebangkrutan adalah kegagalan yang dialami perusahaan dalam menjalankan aktivitas operasi perusahaan untuk menghasilkan laba. Menurut Abrori (2015:24) salah satu cara yang digunakan untuk menghindari risiko kebangkrutan adalah dengan cara menganalisis laporan keuangan yang dimiliki perusahaan. Risiko kebangkrutan dapat mengukur menggunakan metode Altman Z-score Modifikasi yang mengacu pada rasio-rasio keuangan yang dimiliki oleh perbankan yang diperoleh dari laporan neraca dan laporan laba rugi. Rasio tersebut adalah Working Capital to Total Assets, Retained Earning to Total Assets, Earning Before Interest and Taxes to Total Assets, dan Book Value of Equity to Book Value of Total Liabilities. Menurut Lukviarman et al. (2009:19) model Altman Zscore merupakan salah satu pengukuran kinerja kebangkrutan bersifat tidak stagnan melainkan berkembang dari waktu ke waktu, seiring dengan kondisi di mana metode tersebut diterapkan. Metode Altman Z-score Modifikasi adalah metode terbaru dari Altman Z-score yang digunakan untuk menentukan risiko kebangkrutan pada perusahaan jasa, sehingga metode ini lebih tepat untuk menghitung risiko kebangkurutan pada bank (Altman, 2000).

Menurut Nur Falah (2018) penanganan sejak dini terhadap risiko sangat perlu dilakukan. Oleh sebab itu selain mengukur potensi terjadinya kebangkrutan tersebut, bank syariah harus mengetahui faktor-faktor apa saja yang dapat mempengaruhi 
terjadinya kebangkrutan. Sehingga dapat mengetahui upaya yang harus dilakukan untuk mencegah terjadinya potensi kebangkrutan tersebut. Menurut Ben et al. (2015) faktor penyebab kebangkrutan terbagi menjadi dua faktor yaitu, faktor eksternal meliputi kondisi ekonomi, politik, bencana alam serta faktor internal meliputi kinerja perusahaan, kebijakan perusahaan, dan budaya perusahaan. Menurut penelitian Syinta (2018) menyatakan rasio CAR dan FDR memiliki pengaruh yang signifikan terhadap risiko kebangkrutan. Sedangkan menurut Jan dan Marimuthu (2018) menyatakan rasio likuiditas, leverage, profitabilitas dan solvabilitas memiliki pengaruh yang signifikan terhadap risiko kebangkrutan. Kemudian Hasanatika (2016) menggunakan variabel fee based income, bank size, loan asset ratio, cost inefficiency untuk mengukur risiko kebangkrutan bank syariah. Berdasarkan variabel yang digunakan pada penelitian sebelumnya, pada penelitian ini menggunakan variabel yang berasal dari kinerja keuangan untuk mengetahui faktor yang mempengaruhi risiko kebangkrutan pada bank syariah yaitu menggunakan variabel Capital Adequacy Ratio (CAR), Financing to Deposit Ratio (FDR), Rasio Leverage, Bank Size, Loan to Asset Ratio (LAR) dan Return on Asset (ROA).

\section{LANDASAN TEORI}

\section{Risiko}

Susilo (2015) menjelaskan risiko merupakan suatu peristiwa yang memiliki potensi efek negatif yang muncul dari suatu tindakan baik yang sedang dilakukan pada masa sekarang maupun di masa mendatang. Menurut Suganda (2015) risiko dibedakan menjadi dua yaitu risiko internal dan eksternal. Risiko internal adalah risiko yang berasal dari dalam perusahaan itu sendiri seperti kelalaian, human error, korupsi, kesalahan kerja, kesalahan manajemen. Sedangkan risiko eksternal merupakan risiko yang berasal dari luar perusahaan, seperti risiko pencurian, penipuan, bencana alam dan kondisi makro yang tidak stabil.

Menurut Surat Al Hasyr Ayat 18 risiko merupakan sebuah sunatullah, sehingga manusia tidak dapat menghindar dari risiko. Usaha yang dapat dilakukan manusia dalam menghadapi risiko adalah memprediksi dan mengukur terjadinya risiko yang akan dihadapi sebagai upaya untuk mengurangi risiko tersebut. Agama Islam menjelaskan bahwa seluruh apa yang terjadi di muka bumi ini sudah di atur Allah SWT baik itu kematian, rizki, jodoh, kecelakaan serta takdir Allah. Manusia hanya diberikan kesempatan oleh Allah untuk melakukan ikhtiar dan doa. Ikhtiar yang dilakukan adalah dengan melakukan perencanaan dan usaha yang dilakukan dalam menghadapi peristiwa di masa yang akan datang.

\section{Risiko Kebangkrutan}

Menurut Amilia dalam Syinta (2018:14) yang dimaksud dengan kebangkrutan adalah suatu peristiwa kegagalan atau ketidaksanggupan yang dialami perusahaan dalam memenuhi kewajiban kepada debitur karena perusahaan mengalami ketidakcukupan dana untuk menjalankan usahanya sehingga tujuan untuk mencapai 
profit yang diharapkan tidak terpenuhi. Plat dalam Wulandari (2018) menyatakan sebelum terjadi adanya kebangkrutan yang dialami oleh perusahaan, salah satunya adalah terjadinya penurunan kinerja keuangan. Istilah kebangkrutan dapat disamakan dengan istilah financial distress (Autecheva dalam Laila, 2017).

\section{Model dalam Menghitung Risiko kebangkrutan}

Metode yang digunakan untuk menghitung risiko kebangkrutan pada penelitian ini adalah menggunakan Altman Z Score Modifikasi. Metode ini digunakan untuk perusahaan dalam bentuk jasa sehingga menurut Jan dan Marimuthu (2016) metode ini tepat untuk digunakan karena bank termasuk dalam perusahaan jasa. Menurut Altman (2001) merubah persamaan untuk menghitung potensi kebangkrutan sebagai berikut:

$$
Z=6,56 \times 1+3,26 \times 2+6,72 \times 3+1,05 \times 4
$$

\section{Keterangan:}

$$
\begin{array}{cc}
\text { X1 }=\frac{\text { Modal Kerja }}{\text { Total Aset }} & \text { X3 }=\frac{\text { Laba Sebelum Bunga dan Pajak (EBIT) }}{\text { Total Aset }} \\
\text { X2 }=\frac{\text { Laba ditahan }}{\text { Total Aset }} & \text { X4 }=\frac{\text { Book value of equity }}{\text { Book value of total debt }}
\end{array}
$$

Klasifikasi yang diperoleh dari model ini adalah sebagai berikut:

a. Jika nilai $Z<1,1$ maka perusahaan tersebut berada dalam kondisi yang bangkrut.

b. Jika nilai nilai $1,1<Z<2,6$ maka perusahaan tersebut berada dalm kondisi pertengahan, dimana perusahaan tidak ditentukan berada dalam grey area.

c. Jika nilai $Z$ > 2,6 maka perusahaan berada dalam kondisi sehat.

\section{Kinerja Keuangan}

Kinerja bank merupakan gambaran terkait prestasi yang telah dicapai bank selama periode tertentu. Menurut Kasmir (2010:276) capaian ini terkait kemampuan bank syariah dalam menjalankan fungsinya sebagai lembaga intermediasi. Penilaian kinerja bank dapat diukur melalui rasio keuangan yang dimiliki bank syariah. Rasio keuangan ini terdiri dari rasio likuiditas, rasio profitabilitas dan rasio solvabilitas (Kasmir, 2010:281).

\section{Capital Adequacy Ratio (CAR)}

Modal dapat digunakan sebagai penyokong untuk dapat menjalankan kegiatan operasional perusahaan, baik dalam menjalankan dan mengembangkan usaha (Muhammad, 2015: 134). Kecukupan modal yang dimiliki bank harus dapat diperhatikan dengan baik agar tidak menimbulkan terganggunya kegiatan usaha. Kecukupan modal dapat disebut dengan Capital Adequacy Ratio (CAR). 


\section{Financing to Deposit Ratio (FDR)}

Menurut Asnaini (2014) rasio FDR menunjukkan seberapa besar kemampuan bank syariah untuk menyalurkan dana dari pihak ketiga yang dihimpun oleh bank syariah. Rasio FDR merupakan salah satu indikator tingkat kesehatan bank yang mengukur tingkat efisiensi pelaksanaan fungsi bank sebagai lembaga penghimpun dana dan pengalokasiannya (Alfiani dan Mulazid, 2017).

\section{Leverage}

Rasio leverage merupakan rasio yang digunakan untuk mengukur kemampuan perusahaan untuk membayar kewajiban yang dimiliki, baik kewajiban jangka pendek maupun jangka panjang (Setianugraha, 2015:18). Menurut Sandhieko (2009) rasio leverage menggambarkan hubungan antara hutang terhadap modal atau aset yang dimiliki oleh suatu perusahaan.

\section{Bank Size}

Bank size diartikan sebagai ukuran yang dimiliki oleh bank syariah. Menurut Asngari (2013) mengatakan bahwa ukuran bank merupakan suatu skala dimana bank dapat diklasifikasikan berdasarkan besar kecilnya menurut berbagai cara, antara lain berdasarkan total aktiva atau aset yang dimiliki.

\section{Loan to Asset Ratio}

Menurut Dendawijaya (2003:119) Loan to Asset Ratio merupakan rasio yang digunakan untuk mengukur tingkat likuiditas yang dimiliki bank yang menginformasikan terkait kemampuan bank dalam memenuhi kredit nasabah atau penyaluran pembiayaan kepada masyarakat terhadap total aset yang dimiliki oleh bank.

\section{Return on Assets (ROA)}

Menurut Kasmir (2012:197) Return on Assets merupakan perbandingan kemampuan perusahaan dalam menghasilkan keuntungan dengan jumlah seluruh aktiva atau harta yang dimiliki perusahaan dalam periode tertentu. Rasio ROA dapat digunakan sebagai alat untuk menganalisis dan mengukur tingkat efisiensi usaha dan profitabilitas yang dicapai oleh bank bank syariah (Vireyto dan Sulasmiyati, 2017.

\section{METODE PENELITIAN}

\section{Jenis Pendekatan penelitian}

Pendekatan yang digunakan dalam penelitian ini adalah menggunakan pendekatan kuantitatif. Variabel-variabel yang digunakan pada penelitian ini dibagi menjadi dua kelompok variabel, yaitu Variabel Independen yang terdiri dari Capital Adecuacy Ratio (CAR), Financing to Deposit Ratio (FDR), rasio Leverage, Bank Size, 
Loan to Asset Ratio (LAR) dan rasio Return on Asset (ROA), yang kedua Variabel Dependen meliputirisiko kebangkrutan bank umum syariah di Indonesia. Data variabel yang digunakan diperoleh dari laporan tahunan masing-masing Bank Umum Syariah yang dipublikasikan melalui website resmi bank selama periode 2011-2017.

\section{Populasi dan Sampel}

Populasi yang digunakan dalam penelitian ini adalah Bank Umum Syariah di Indonesia dengan waktu pengamatan selama periode 2011-2017. Dalam penelitian ini pengambilan sampel dilakukan dengan menggunakan teknik purposive sampling. Terdapat 10 bank syariah yang digunakan sebagai sampel penelitian yaitu Bank Victoria Syariah, Bank Muamalat Indonesia, Bank BRI Syariah, Bank Jabar Banten Syariah, Bank BNI Syariah, Bank Syariah Mandiri, Bank Mega Syariah, Bank Panin Dubai Syariah, Bank Bukopin Syariah dan Bank BCA Syariah.

\section{Teknik Analisis Data}

Penelitian ini menggunakan pendekatan kuantitatif dengan teknik analisis regresi data panel. Data yang digunakan dalam analisis panel merupakan gabungan antara data time series dan cross section. Data ini dapat diperoleh melalui pengamatan serangkaian observasi antar individu (cross section) pada suatu periode tertentu (Ariefianto, 2012:148). Menurut Gujarati (2012:237) uji asumsi klasik tidak diperlukan dalam analisis data panel karena data panel dapat meminimalkan terjadinya bias, masalah heterogenitas maupun autokorelasi yang kemungkinan terjadi dalam hasil analisis data panel yang dilakukan. Selain itu, data panel dapat memberi lebih banyak informasi, variasi, serta dapat meningkatkan derajat kebebasan yang dapat meningkatkan efisiensi model.

Baltagi (2005:18) menjelaskan bahwa terdapat satu uji yang digunakan yaitu Uji Hausman untuk mengetahui model mana yang paling tepat untuk digunakan, yaitu antara fixed effect model (FEM) atau random effect model (REM). Rumusan Hipotesis yang ditentukan dalam uji Hausmann adalah sebagai berikut :

$\mathrm{HO}:$ Random Effect Model

\section{H1 : Fixed Effect Model}

Menurut Widarjono, (2013:365) hasil Uji Hausman dilihat berdasarkan P Value dari tabel Chi-Square. Apabila nilai $\mathrm{P}$ Value < tingkat signifikasi $(\alpha) 5 \%$, maka $\mathrm{HO}$ ditolak dan menerima $\mathrm{H} 1$ yang menyatakan bahwa pemilihan estimasi data panel sebaiknya menggunakan fixed effect model (FEM). Sebaliknya, P Value > tingkat signifikasi $(\alpha)$ sebesar $5 \%$, maka HO diterima dan menolak $\mathrm{H} 1$, ini artinya pemilihan estimasi data panel sebaiknya menggunakan Random Effect Model. 


\section{Uji Hipotesis}

\section{Uji Simultan (Uji F)}
a. $H_{0}: \beta_{1}=\beta_{2}=\beta_{3}=\beta_{4}=\beta_{5}=\beta_{6}=0$
b. $H_{1}: \beta_{1} \neq \beta_{2} \neq \beta_{3} \neq \beta_{4} \neq \beta_{5} \neq \beta_{6} \neq 0$

Dasar pengambilan keputusan dilakukan dengan cara membandingkan dengan tingkat signifikansi F-statistik dengan $\alpha$ sebesar 0,05. Apabila nilai F-statistik < nilai $\alpha$, maka $\mathrm{H}_{0}$ ditolak dan menerima $\mathrm{H}_{1}$ yang menyatakan bahwa variabel Capital Adequacy Ratio (CAR), Financing to Deposit Ratio (FDR), Rasio Leverage, Bank Size, Loan to Asset Ratio dan Return On Asset (ROA) berpengaruh signifikan secara simultan terhadap risiko kebangkrutan pada Bank Umum Syariah di Indonesia.

\section{Uji Parsial (Uji T)}

a. $H_{0}: \beta_{n}=0$

b. $H_{1}: \beta_{n} \neq 0$

Dasar pengambilan keputusan dilakukan dengan cara membandingkan dengan tingkat signifikansi T-statistik dengan $\alpha$ sebesar 0,05. Jika nilai T-statistik $<\alpha$, maka $\mathrm{H}_{0}$ ditolak dan menerima $\mathrm{H}_{1}$ yang menyatakan bahwa variabel Capital Adequacy Ratio (CAR), Financing to Deposit Ratio (FDR), Rasio Leverage, Bank Size, Loan to Asset Ratio dan Return On Asset (ROA) berpengaruh signifikan secara parsial terhadap risiko kebangkrutan pada Bank Umum Syariah di Indonesia.

\section{Koefisien Determinasi $\left(\mathbf{R}^{2}\right)$}

Uji koefisien determinasi $\mathrm{R}_{2}$ bertujuan untuk mengukur seberapa besar kemampuan model dalam menerangkan variasi dari variabel dependen (Nachrowi, 2002:21).

\section{HASIL DAN PEMBAHASAN \\ Model Regresi Data Panel}

Berdasarkan hasil uji hausman tabel 4.1 di bawah ini menunjukkan nilai probabilitas Cross Section Random sebesar 0,3111 di mana nilai tersebut lebih besar dari tingkat signifikansinya $(\alpha) 5 \%$ model terbaik yang digunakan adalah Random Effect Model. 


\section{Tabel 1}

\section{Hasil Uji Hausman}

Correlated Random Effects - Hausman Test

Equation: Untitled

Test cross-section random effects

\begin{tabular}{lrrr}
\hline \hline Test Summary & Chi-Sq. Statistic & Chi-Sq. d.f. & Prob. \\
\hline \hline Cross-section random & 7.106533 & 6 & 0.3111 \\
\hline \hline
\end{tabular}

Sumber: data olahan Eviews 9.0

Hasil dari olahan data panel disajikan pada tabel 2.2 di bawah ini:

Tabel 2

Hasil Analisis Regresi data Panel - Random Effect Model

\begin{tabular}{ccccc}
\hline $\begin{array}{c}\text { Variabel } \\
\text { Independen }\end{array}$ & Koefisien & t-statistik & Prob. & Kesimpulan \\
\hline C & $-38.309,81$ & $-3,373101$ & 0,0013 & Signifikan \\
CAR & 14,19912 & 7,612696 & 0,0000 & Signifikan \\
FDR & 9,916544 & 8,954734 & 0,0000 & Signifikan \\
Leverage & $-4,062485$ & $-5,134739$ & 0,0000 & Signifikan \\
Bank Size & 0,162936 & 2,427242 & 0,0181 & Signifikan \\
Loan to Asset Ratio & $-1,619036$ & $-2,047172$ & 0,0448 & Signifikan \\
ROA & 2,567114 & 0,389389 & 0,6983 & Tidak Signifikan \\
\hline
\end{tabular}

Sumber: data olahan Eviews 9.0

Berdasarkan hasil pengujian analisis regresi data panel di atas, kemudian dapat ditulis persamaan model regresi sebagai berikut:

$$
\begin{aligned}
\text { Zscore }= & -38.309,81+14,19912 \mathrm{CAR}+9,916544 \mathrm{FDR}-4,062485 \mathrm{Lev}+0,162936 \mathrm{BZ}- \\
& \text { 1,619036LAR }+2,567114 \mathrm{ROA}
\end{aligned}
$$

\section{Uji Hipotesis}

Uji Simultan (F-test)

Tabel 3

Hasil Uji Simultan (F-test)

\begin{tabular}{cc}
\hline F-statistic & 45,31570 \\
Prob. (F-statistic) & 0,000000 \\
\hline
\end{tabular}

Sumber: data olahan Eviews 9.0

Berdasarkan tabel 4.3 di atas dapat diketahui bahwa nilai signifikansinya Prob. (F-statistic) sebesar 0.000000 , lebih besar dari pada nilai signifikasi $(\alpha) 0,05$. Rasio CAR, FDR, leverage, bank size, loan to asset ratio dan ROA berpengaruh signifikan secara simultan terhadap nilai Altman z-score bank umum syariah. 
Uji Parsial (T-test)

Tabel 4

Hasil Uji Parsial (T-test)

\begin{tabular}{cccc}
\hline Variabel & t-statistic & Prob & Keterangan \\
\hline CAR & 7,612696 & 0,0000 & Signifikan \\
FDR & 8,954734 & 0,0000 & Signifikan \\
Leverage & $-5,134739$ & 0,0000 & Signifikan \\
Bank Size & 2,427242 & 0,0181 & Signifikan \\
Loan to Asset Ratio & $-2,047172$ & 0,0448 & Signifikan \\
ROA & 0,389389 & 0,6983 & Tidak Signifikan \\
\hline
\end{tabular}

Sumber: data olahan Eviews 9.0 (Lampiran) 5

Berdasarkan tabel 4.4 di atas dapat diketahui Rasio CAR, FDR, leverage, bank size, dan loan to asset ratio berpengaruh signifikan dan ROA secara berpengaruh tidak signifikan terhadap nilai Altman z-score bank umum syariah.

Analisis Koefisien Determinasi $\left(\mathbf{R}^{2}\right)$

Hasil analisis regresi data panel menunjukkan nilai $R^{2}$ ( $R$-squared) sebesar 0.811881 (81,18\%). Dapat disimpulkan bahwa variabel independen meliputi CAR, FDR, leverage, bank size, loan to asset ratio dan ROA dapat menjelaskan pengaruhnya terhadap Altman Z-score sebesar $81,18 \%$ dan sisanya sebesar 18,82\% dijelaskan variabel lain diluar variabel independen yang digunakan dalam penelitian ini.

\section{Pengaruh CAR Terhadap Risiko Kebangkrutan Bank Umum Syariah}

Rasio CAR berpengaruh signifikan terhadap risiko kebangkrutan yang sejalan dengan penelitian Syinta (2018) dan Khadapi (2017). Rasio CAR digunakan untuk mengelola aset berisiko berupa kredit, penyertaan, surat berharga, tagihan pada bank lain dengan modal yang dimiliki bank syariah (Dendawijaya, 2003:122). Sehingga rasio CAR dapat menjadi kekuatan modal bagi bank syariah dalam menanggung aset berisiko bank syariah. Menurut Purnamandari dan Badera (2015) modal dapat digunakan sebagai pelindung bank syariah dalam menghadapi kegagalan dan sebagai kekuatan bank syariah dalam menghadapi persaingan di pasar perbankan. Menurut Peraturan Bank Indonesia Nomor 15/ 12 /PBI/2013 Tentang Kewajiban Penyediaan Modal Minimum Bank Umum menyatakan bahwa rasio CAR yang harus dimiliki oleh bank syariah minimal adalah $8 \%$. Oleh sebab itu bank syariah harus berusaha menjaga rasio CAR yang dimiliki agar berada di atas batas yang telah ditetapkan oleh Bank Indonesia.

\section{Pengaruh FDR Terhadap Risiko Kebangkrutan Bank Umum Syariah}

Al Qur'an dan Hadits menjelaskan bahwa harta tidak boleh ditimbun atau diputar pada orang-orang tertentu saja, melainkan harus dapat didistribusikan secara merata di semua kalangan sesuai dengan firman Allah dalam Surat Al Hasyr ayat 7 yang menyatakan tentang perintah kepada manusia terkait pendistribusian. Jan dan Marimuthu (2016) rasio FDR digunakan sebagai salah satu tolak ukur dari kinerja 
bank syariah. Selain itu, rasio FDR yang tinggi mengindikasikan bahwa bank syariah memiliki sistem manajemen yang baik dalam hal pengelolaan dana yang dimiliki (Syinta, 2018). Dengan kondisi ini dapat menurunkan terjadinya risiko kebangkrutan yang akan dihadapi oleh bank syariah. Menurut Surat Edaran Bank Indonesia No. 12/19/PBI/2010 menyatakan bank syariah dikatakan efisien dalam menjalankan fungsi intermediasi apabila memiliki rasio FDR antara 80\%-100\%. Oleh sebab itu bank syariah harus menjaga rasio FDR dalam kondisi yang aman serta dapat mengontrol tingkat likuiditas bank agar terjaga sesuai dengan ketentuan Bank Indonesia.

\section{Pengaruh Leverage Terhadap Risiko Kebangkrutan Bank Umum Syariah}

Menurut Muhammad (2015:139) hutang bukanlah sumber modal utama yang dipilih oleh bank syariah, sebab dari transaksi hutang memiliki dampak buruk yang mungkin akan dihadapi yaitu terjadinya kesulitan pembayaran apabila terlalu banyak modal yang diperoleh dari hutang. Rasio leverage memiliki pengaruh signifikan terhadap risiko kebangkrutan bank syariah sejalan dengan penelitian Jan dan Marimuthu (2016) dan Marin (2013). Bank syariah yang pembiayaannya lebih banyak menggunakan utang, akan menimbulkan risiko kesulitan dalam melakukan pembayaran di masa yang akan datang dikarenakan nilai utang yang lebih besar dibandingkan aset yang dimiliki (Yustika, 2015). Apabila keadaan ini terus terjadi dan tidak dapat diatasi dengan baik, maka akan menimbulkan terjadinya potensi kebangkrutan yang besar yang akan dialami oleh bank syariah. Hasil ini juga diperkuat oleh pendapat dari Blum (1974) yang menyatakan ketidakmampuan perusahaan dalam membayar kewajiban yang dimiliki pada saat jatuh tempo menjadi faktor yang menyebabkan terjadinya risiko kebangkrutan yang dialami perusahaan.

\section{Pengaruh Bank Size Terhadap Risiko Kebangkrutan Bank Umum Syariah}

Bank size memiliki pengaruh yang signifikan terhadap risiko kebangkrutan bank penelitian sejalan dengan Purnamandari dan Badera (2015) serta Bestari dan Rohman (2013). Bank syariah yang memiliki ukuran yang lebih besar dapat memiliki kemampuan yang lebih besar pula dalam melakukan diversifikasi terhadap risiko yang dihadapi (Hasanatina, 2016). Bank syariah yang memiliki kualitas aset yang baik dapat terhindar dari keadaan bermasalah yang mungkin akan dihadapi salahsatunya terkait potensi kebangkrutan (Bestari dan Rohman, 2013).

Menurut Kumar, dkk (2001) menjelaskan ukuran perusahaan memiliki hubungan dengan teori economics of scale. Di dalam teori teknologi menekankan economics of scale menggunakan aset sebagai ukuran bank. Hal ini dikarenakan teori ini memfokuskan pada proses produksi dan investasi pada modal fisik yang diperlukan untuk menghasilkan output. Perkembangan dari teknologi yang digunakan dapat meningkatkan ukuran perusahaan. Sehingga di dalam bank syariah, ukuran bank yang besar dapat semakin meningkatkan kepercayaan investor dan nasabah untuk melakukan investasi maupun pembiayaan kepada bank syariah. Sehingga 
Pengaruh Kinerja Keuangan Terhadap Risiko Kebangkrutan Bank Umum Syariah...

peluang terjadinya risiko kebangkrutan dapat semakin rendah dengan besarnya kepercayaan nasabah terhadap bank syariah. Selain itu, semakin besar ukuran bank syariah maka akan meningkatkan kestabilan bank dalam menghadapi keadaan ekonomi (Hasanatina, 2016).

\section{Pengaruh Loan to Asset Ratio Terhadap Risiko Kebangkrutan Bank Umum Syariah}

Tingginya Loan to Asset Ratio menyebabkan likuiditas bank syariah menurun dikarenakan aset yang dimiliki terlalu banyak digunakan untuk membiayai pembiayaan yang disalurkan (Hasanatina, 2016). Masalah likuiditas muncul karena adanya masalah pada kegiatan pembiayaan sehingga bank tidak dapat memenuhi kewajibannya dengan segera (Hasibuan, 2001:87). Apabila hal ini terus terjadi maka dapat menimbulkan kegagalan pada bank yang berdampak pada terjadinya risiko kebangkrutan yang akan dialami oleh bank syariah. Oleh sebab itu bank syariah perlu mengontrol jumlah aset yang dimiliki untuk membiayai pembiayaan yang disalurkan pada batas yang wajar. Rahman (2010) juga menyatakan bahwa loan to asset ratio memiliki pengaruh yang signifikan terhadap risiko kebangkrutan bank syariah.

\section{Pengaruh ROA Terhadap Risiko Kebangkrutan Bank Umum Syariah}

ROA memiliki pengaruh yang tidak signifikan terhadap risiko kebangkrutan bank syariah yang sejalan penelitian Khadapi (2017) dan Rohmadini, dkk (2018). ROA merupakan kemampuan bank syariah dalam menghasilkan laba dengan aset yang dimiliki secara efektif dan efisien. Pada umumnya rasio ROA yang rendah dapat menimbulkan financial distress yang dapat mengarah pada risiko kebangkrutan (Marfungatun, 2017). Akan tetapi kondisi ini belum tentu terjadi seperti itu, sebab selama bank syariah mampu memiliki kecukupan modal untuk menanggung risiko yang dihadapi dan memiliki likuiditas yang cukup serta dapat melakukan pengelolaan secara efektif dan efisien terhadap seluruh beban yang dimiliki, maka rasio ROA tidak akan terlalu berdampak kepada risiko kebangkrutan bank syariah.

Menurut Kaufman (1996) menjelaskan bahwa terdapat empat faktor yang menyebabkan terjadinya risiko kebangkrutan bank yaitu adanya ekspansi kredit yang tidak terkontrol, informasi asimetri, semakin berkurangnya nasabah yang menempatkan dana di bank dan adanya permasalahan terkait hukum yang berdampak pada terjadinya kebangkrutan. Beaver (1967) juga megatakan bahwa risiko kebangkrutan perusahaan disebabkan karena adanya ketidak mampuan dalam melunasi hutang yang dimiliki pada saat jatuh tempo.

\section{Pengaruh CAR, FDR, Leverage, Bank Size, Loan to Asset Ratio dan ROA Terhadap Risiko Kebangkrutan Bank Umum Syariah}

Risiko kebangkrutan harus dapat dicegah dan dihindari oleh setiap bank syariah agar dapat tetap tumbuh dan berkembang dalam pasar perbankan di Indonesia serta dapat terhindar dari penutupan bank akibat kepailitan. Bank syariah perlu mengetahui seberapa besar risiko kebangkrutan yang mungkin dihadapi serta 
faktor yang menimbulkan terjadinya risiko kebangkrutan. Oleh sebab itu bank syariah harus dapat mengelola, meminimalisir atau bahkan mencegah terjadinya risiko yang akan dihadapi. Allah SWT berfirman dalam surat AI Yusuf ayat 46-49 yang berbunyi:

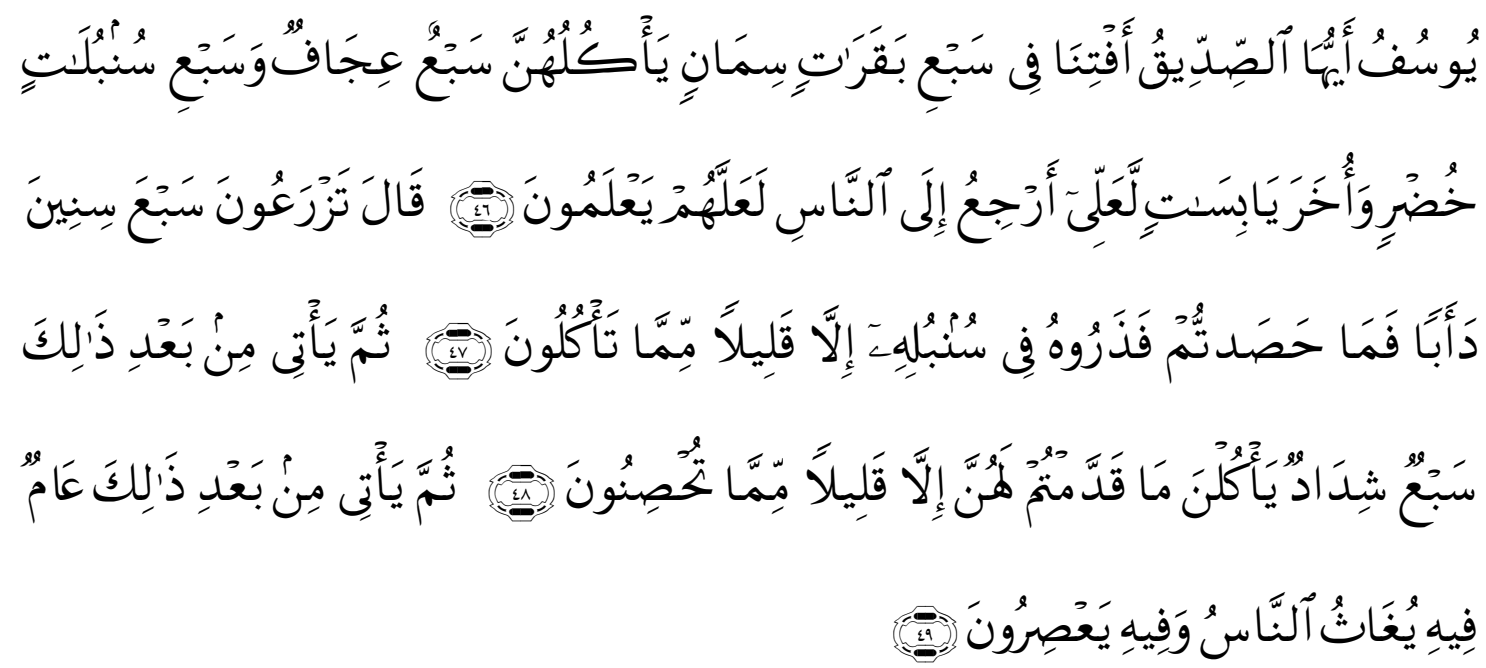

yụsufu ayyuhaș-șiddīqu aftinā fĩ sab'i baqarātin simāniy ya kuluhunna sab'un 'ijāfuw wa sab'i sumbulātin khuḍriw wa ukhara yābisātil la'allī arji'u ilan-nāsi la'allahum ya'lamụn (46) qāla tazra'ụna sab'a sinīna da'abā, fa mā hașattum fa żarụhu fi sumbulihī illā qalīlam mimmā ta kulụn (47) summa ya 'ti mim ba'di żālika sab'un syidāduy ya kulna mā qaddamtum lahunna illā qalīlam mimmā tuhșinụn (48) summa ya 'tì mim ba'di żālika 'āmun fỉhi yugāsiun-nāsu wa fïhi ya'șirụn (49)

Artinya: "(Setelah pelayan itu berjumpa dengan Yusuf dia berseru): "Yusuf, hai orang yang amat dipercaya, terangkanlah kepada kami tentang tujuh ekor sapi betina yang gemuk-gemuk yang dimakan oleh tujuh ekor sapi betina yang kurus-kurus dan tujuh bulir (gandum) yang hijau dan (tujuh) lainnya yang kering agar aku kembali kepada orang-orang itu, agar mereka mengetahuinya. Yusuf berkata: "Supaya kamu bertanam tujuh tahun (lamanya) sebagaimana biasa; maka apa yang kamu tuai hendaklah kamu biarkan dibulirnya kecuali sedikit untuk kamu makan. Kemudian sesudah itu akan datang tujuh tahun yang amat sulit, yang menghabiskan apa yang kamu simpan untuk menghadapinya (tahun sulit), kecuali sedikit dari (bibit gandum) yang kamu simpan. Kemudian setelah itu akan datang tahun yang padanya manusia diberi hujan (dengan cukup) dan dimasa itu mereka memeras anggur." (QS.12:46-49, Departemen Agama RI, 2018).

Berdasarkan Surat Yusuf ayat 46-49 menjelaskan mengenai kisah Nabi Yusuf yang mengisahkan pada tujuh tahun kedua di zaman beliau akan timbul kekeringan yang dahsyat. Ini merupakan suatu risiko yang menimpa negeri Yusuf tersebut. Namun Nabi Yusuf telah melakukan pengukuran dan pengendalian atas risiko yang akan terjadi pada tujuh tahun kedua tersebut melalui mimpinya. Oleh sebab itu setiap manusia diperintahkan agar selalu berusaha untuk mempersiapkan apa yang mungkin terjadi di masa yang akan datang yang menimbulkan dampak merugikan. 
Pengaruh Kinerja Keuangan Terhadap Risiko Kebangkrutan Bank Umum Syariah...

Karena manusia tidak dapat mengetahui secara pasti apa yang akan terjadi kedepannya. (Shihab, 2002:109-113).

Pengelolaan risiko sangat penting dilakukan oleh manusia untuk mencegah terjadinya sesuatu yang merugikan. Sehingga muncul adanya istilah yang bernama manajemen risiko. Dalam bank syariah manajemen risiko juga sangat diperlukan untuk mengantisipasi kerugian yang mungkin akan dialami bank akibat kondisi yang terjadi baik berasal dari dalam maupun luar bank syariah. Oleh sebab itu bank syariah perlu mengetahui faktor-faktor apa saja yang dapat menimbulkan terjadinya risiko kebangkrutan. Kemudian dari faktor-faktor tersebut bank syariah dapat melakukan upaya untuk dapat meminimalisir atau bahkan menghindari terjadinya risiko kebangkrutan karena telah melakukan tindakan manajemen risiko sejak dini dengan cara yang tepat.

\section{SIMPULAN}

Berdasarkan hasil penelitian yang telah dilakukan menunjukkan bahwa kinerja keuangan yang diukur melalui variabel Capital Adequacy Ratio, Financing to Deposit Ratio, Leverage, Bank Size, Loan to Asset Ratio dan Return on Asset berpengaruh signifikan secara simultan terhadap risiko kebangkrutan. Sedangan secara parsial variabel Capital Adequacy Ratio, Financing to Deposit Ratio, Bank Size berpengaruh positif signifikan, variabel Rasio Leverage Loan to Asset Ratio berpengaruh negatif signifikan serta Return on Asset berpengaruh positif tidak signifikan terhadap nilai Altman Z-Score sebagai pengukur risiko kebangkrutan pada bank umum syariah di Indonesia.

Saran yang dapat diberikan dari penelitian ini adalah diharapkan bank umum syariah dapat memperhatikan dan mengontrol kondisi internal bank terkait kinerja keuangan yang dapat mempengaruhi terjadinya risiko kebangkrutan yaitu kondisi Capital Adequacy Ratio, Financing to Deposit Ratio, Rasio Leverage, Bank Size dan Loan to asset ratio, Investor dan nasabah yang menggunakan produk di bank umum syariah diharapkan memperhatikan rasio-rasio kinerja keuangan yang dapat mempengaruhi risiko kebangkrutan bank umum syariah agar tidak menimbulkan kerugian serta bagi penelitian selanjutnya dapat menambahkan variabel lain yang berasal dari eksternal bank syariah terkait kondisi ekonomi dan kebijakan yang ditetapkan oleh Bank Indonesia yaitu variabel makro, seperti tingkat suku bunga, inflasi, nilai tukar dan PDB (Produk Domestik Bruto). Selain itu dapat menambah sampel penelitian tidak hanya pada bank umum syariah namun juga dapat meneliti kebangkrutan perbankan syariah secara umum dengan menambahkan unit usaha syariah dan BPRS syariah. 
Afiqoh dan Laila | Jurnal Ekonomi dan Bisnis Islam, Vol. 4, No. 2, Juni - Des. 2018

\section{DAFTAR PUSTAKA}

Abdurrahman. Syaikh. (2016). Tafsir Al Quran Sura Al Mu'minun, an Nur, al-Furqan, asy-Syu'ara, an-Naml, al Qashash, alAnkabut, ar-Rum, Luqman, as-Sajdah, alAhzab, Saba' Jilid 5. Jakarta: Darul Haq.

Abrori, Hilman. (2015). Analisis Perbandingan Risiko Kebangkrutan pada Bank Syariah Devisa dan Non Devisa dengan Menggunakan Metode Altman Z-Score Periode 2010-2012. Skripsi Diterbitkan. Semarang: Fakultas Ekonomi Dan Bisnis Islam Universitas Islam Negeri Walisongo.

Aji, Rifki Satriyo. (2017). Proses Manajemen Risiko Gadai Emas Baitul Maal Wat Tamwil Usaha Gabungan Terpadu Sidogiri Cabang Klampis Bangkalan Madura. Jurnal Ekonomi Syariah Teori dan Terapan.4(11), 902-913.

Anshori, Muslich dan Sri Iswati. 2009. Metode Penelitian Kuantitatif. Surabaya: Pusat

Asnaini, Sri Wahyuni. 2014. Faktor-Faktor Yang Mempengaruhi Non Performing Financing (NPF) Pada Bank Umum Syariah di Indonesia. Jurnal TEKUN. 5(2), 264-280.

Altman, E.I. (2000), Predicting financial distress of companies: Revisiting the Z-score and zeta models. Journal of Banking \& Finance. 9-12.

Beaver, W. H. (1967). Financial Ratio as Predictors of Failure. Empirical Research in Accounting: Selected Studies, Supplement to Vol 5, Journal of Accounting Research, 71-102.

Ben, Ditiro Alam, et al. (2015). Analisis Metode Springate (S-Score) Sebagai Alat Untuk Memprediksi Kebangkrutan Perusahaan (Studi pada Perusahaan Property dan Real estate yang listing di Bursa Efek Indonesia pada Tahun 2011-2013). Jurnal Administrasi Bisnis. 21(1), 1-9.

Bestari, Adhistya Rizky dan Abdul Rohman. (2013). Pengaruh Rasio Camel dan Ukuran Bank Terhadap Prediksi Kondisi Bermasalah pada Sektor Perbankan (Studi Pada Perusahaan Perbankan yang Terdaftar Di Bursa Efek Indonesia Tahun 2007 - 2011). Diponegoro Journal of Accounting. 2(3), Hal. 1-9.

Blum, N. (1974). Failing Company Discriminant Analysis. Journal of Accounting Research. 12(1); 1-25

Dendawijaya, Lukman. (2003). Manajemen Perbankan. Jakarta: Ghalia Indonesia.

Departemen Agama RI. (2017). Al-Qur'an Mushaf Al Quran Terjemah, Jakarta: Al Huda.

Gujarati dan Porter. (1992). Dasar-dasar Ekonometrika. Jakarta. Salemba Empat

Gujarati, Damodar. (2012). Dasar-Dasar Ekonometrika. Jakarta: Salemba Empat

Hasanatina, Foza Hadyu dan Wisnu Mawardi. (2016). Analisis Risiko Kebangkrutan Bank Syariah dengan Metode Zscore (Studi Kasus pada Bank Umum Syariah di Indonesia periode 2008-2014). Diponegoro Journal of Management. 5(2), 1-10 
Hayes, Suzanne K, et al. (2010). A Study of the Efficacy of Altman's Z to Predict Bankruptcy of Specialty Retail Firms Doing Business in Contemporary Times. Economics \& Business Journal. 3(1), Hal 122-134.

Jan, Amin and Maran Marimuthu. (2015). Altman Model and Bankruptcy Profile of Islamic Banking Industry: A Comparative Analysis on Financial Performance. International Journal of Business and Management. 10(7), 110-119.

Jan, Amin and Maran Marimuthu. (2016). Bankruptcy Profile of Foreign versus Domestic Islamic Banks of Malaysia: A Post Crisis Period Analysis. International Journal of Economics and Financial Issues. 6(1), 332-346.

Kamaludin, Arief. (2017). Banyak Tantangan, Pangsa Pasar Perbankan Syariah Baru 5,5\%. Diperoleh dari https://katadata.co.id/berita/2017/12/15/banyaktantangan-pangsa-pasar-perbankan-syariah-baru-55.

Kasmir. (2010). Manajemen Perbankan. Jakarta: PT Raja Grafindo Persada.

Kasmir. (2012). Analisis Laporan Keuangan. Jakarta: PT Raja Grafindo Persada.

Khadapi, Muamar. Pengaruh CAR, ROA, BOPO, dan FDR Terhadap Financial Distress Bank Umum Syariah di Indonesia Periode 2014-2016. Skripsi Diterbitkan. Jakarta: Fakultas Ekonomi dan Bisnis Universitas Islam Negeri Syarif Hidayatullah.

Kumar, K.B. and R.G. Rajan and L. Zingales, (2001). What determines firm size? Working Paper. University of Chicago.

Laila, Nisful dan Faris Widihadnanto. (2017). Financial Distress Prediction Using Bankometer Model on Islamic and Conventional Banks: Evidence from Indonesia. International Journal of Economics and Management (IJEM) 11 (S1), 169-181.

Lukviarman, Niki dan Ayu Suci Ramdhani. "Perbandingan Analisis Prediksi Kebangkrutan Menggunakan Model Altman Pertama, Altman Revisi, dan Altman Modifikasi Dengan Ukuran dan Umur Perusahaan Sebagai Variabel Penjelas". Jurnal Siasat Bisnis. 13(1), 15-28.

Marfungatun, Fitri. (2017). Pengaruh Rasio Profitabilitas, Likuiditas dan Leverage Terhadap Kondisi Financial Distress Perusahaan Manufaktur yang Terdaftar di Bursa Efek Indonesia. Artikel Universitas PGRI Yogyakarta.

Marin, M. (2013), Can financial risk management help prevent bankruptcy? Journal of Finance and Accountancy, 12, 1.

Muhammad. (2015). Manajemen Dana Bank Syariah. Jakarta: Rajawali Pers.

Nachrowi, Djalal dan Hardius Usman. (2002). Penggunaan Teknik Ekonometri. Jakarta: PT Raja Grafindo Persada.

Hurfalah, Irfan dkk. (2018). Early Warning to Banking Crises in The Dual Financial System in Indonesia: The Markov Switching Approach. Journal of King Abdul Aziz University. 31 (2), 133-156. 
Oktarina, Eka. (2017). Analisis Prediksi Kebangkrutan dengan Metode Altman Z Score pada PT BRI Syariah. Skripsi Diterbitkan. Palembang: Fakultas Ekonomi dan Bisnis Universitas Islam Negeri Raden Patah.

Ohlson, J. A. (1980), Financial ratios and the probabilistic prediction of bankruptcy. Journal of Accounting Research, 18, 109-131.

Sandhieko, Hendri Haryo. (2009). Analisis Rasio Likuiditas, Rasio Leverage, dan Rasio Profitabilitas Serta Pengaruhnya Terhadap Harga Saham pada Perusahaan Sektor Pertambangan yang Listing di BEl. Skripsi diterbitkan. Fakultas Bisnis dan Manjemen Universitas Widyatama.

Setianugraha, Herman. (2015). Analisis Rasio Keuangan untuk Menilai Kinerja Keuangan Perusahaan (Studi Kasus Pada Perusahaan Pertambangan yang Terdaftar di Bursa Efek Indonesia Tahun 2008-2012). Skripsi Diterbitkan. Makassar: Fakultas Ekonomi dan Bisnis Univeristas Hassanudin.

Shihab, Quraish. (2002). Tafsir Al Mishbah: Pesan, Kesan dan Keserasian Al Quran. Jakarta: Lentera Hati.

Statistik Perbankan Syariah, Otoritas Jasa Keuangan

Suganda, Asep Dadan. (2015). Mengurangi Tingkat Risiko Dengan Manajemen Islami. Jurnal Ekonomi Islam. 6(2), 1-14.

Syinta, Noer. (2018). Faktor Internal dan Eksternal yang Mempengaruhi Potensi Kebangkrutan Bank Umum Syariah di Indonesia (Metode Altman Z-Score Modifikasi). Skripsi Diterbitkan. Jakarta: Fakultas Ekonomi dan Bisnis Universitas Islam Negeri Syarif Hidayatullah.

Undang-Undang Nomor 21 Tahun 2008 Tentang Perbankan Syariah.

Vireyto, Nikita dan Sulasmiyati, Sri. (2017). Analisis Pengaruh Return on Asset, Return on Equity, dan Earning Per Share Terhadap Harga Saham (Studi Pada Perusahaan Bank Bumn Yang Listed di Bursa Efek Indonesia Periode 20062016). Jurnal Administrasi Bisnis (JAB). 51(1), 75-85.

Widarjono, Agus. (2013). Ekonometrika: Teori dan Aplikasi untuk Ekonomi dan Bisnis Edisi Lima. Yogyarakta: Ekonosia Fakultas Ekonomi UII.

Yustika, Yeni. (2015). Pengaruh Likuiditas, Leverage, Profitabilitas Operating Capacity dan Biaya Agensi Manajerial Terhadap Financial Distress (Studi Empiris pada Perusahaan Manufaktur yang Terdaftar di Bursa Efek Indonesia Tahun 20112013). Jom FEKON. 2(2), 1-15. 